\title{
Cyclosporin safety in a simplified rat brain tumor implantation model
}

\section{Segurança do tratamento com ciclosporina em um modelo pré-clínico de tumor cerebral experimental em ratos}

\author{
Francisco H. C. Felix , Juvenia B. Fontenele², Milena G. Teles³, João E. Bezerra Neto³, Márcia H. A. M. \\ Santiago ${ }^{3}$, Roberto L. Picanço Filho ${ }^{3}$, Dalgimar B. de Menezes ${ }^{4}$, Glauce S. B. Viana ${ }^{5}$, Manoel O. de Moraes ${ }^{5}$
}

\begin{abstract}
Brain cancer is the second neurological cause of death. A simplified animal brain tumor model using W256 (carcinoma 256 , Walker) cell line was developed to permit the testing of novel treatment modalities. Wistar rats had a cell tumor solution inoculated stereotactically in the basal ganglia (right subfrontal caudate). This model yielded tumor growth in 95\% of the animals, and showed absence of extracranial metastasis and systemic infection. Survival median was 10 days. Estimated tumor volume was $17.08 \pm 6.7 \mathrm{~mm}^{3}$ on the $7^{\text {th }}$ day and $67.25 \pm 19.8 \mathrm{~mm}^{3}$ on $9^{\text {th }}$ day post-inoculation. Doubling time was $24.25 \mathrm{~h}$. Tumor growth induced cachexia, but no hematological or biochemical alterations. This model behaved as an undifferentiated tumor and can be promising for studying tumor cell migration in the central nervous system. Dexamethasone $3.0 \mathrm{mg} / \mathrm{kg} /$ day diminished significantly survival in this model. Cyclosporine $10 \mathrm{mg} / \mathrm{kg} / \mathrm{day}$ administration was safely tolerated.
\end{abstract}

Key words: brain neoplasms, neoplasms, experimental, carcinoma 256, Walker, cachexia, cell movement, immunosuppressive agents.

\begin{abstract}
RESUMO
Neoplasias encefálicas constituem a segunda causa neurológica de morte. Foi desenvolvido um modelo animal simplificado de tumor cerebral em ratos utilizando a linhagem celular W256 (carcinoma 256 de Walker) para permitir teste de novos tratamentos. Ratos Wistar foram inoculados nos gânglios da base (caudato subfrontal direito) com uma solução celular tumoral, por via estereotáxica. Este modelo demonstrou crescimento tumoral em 95\% dos animais inoculados com sucesso, além de mostrar ausência de metástases extracranianas e infecção sistêmica. A mediana de sobrevida dos animais foi de 10 dias. O volume tumoral estimado foi de $17,08 \pm 6,7 \mathrm{~mm}^{3}$ no sétimo dia e de $67,25 \pm 19,8 \mathrm{~mm}^{3}$ no nono dia após a inoculação. 0 tempo de duplicação foi estimado em 24,25 h. 0 crescimento tumoral induziu a caquexia, mas não houve alterações bioquímicas ou hematológicas. Esse modelo permite fácil reprodução e comporta-se como um tumor indiferenciado, mostrando potencial para estudar migração celular tumoral no sistema nervoso central. Dexametasona 3,0 mg/kg/dia reduziu significantemente a sobrevida dos animais inoculados com tumor nesse modelo. Ciclosporina $10 \mathrm{mg} / \mathrm{kg} / \mathrm{dia}$ não teve efeito na sobrevida, sendo sua administração bem tolerada.
\end{abstract}

Palavras-Chave: neoplasias encefálicas, neoplasias experimentais, carcinoma 256 de Walker, caquexia, movimento celular, imunossupressores.

There is a continuing need for experimental neuro-oncology for animal models that can be used to assess the efficacy of innovative approaches for the treatment of brain tumors. The rat has been one of the most widely used of all experimental animals, and rat brain tumor models have been used extensively since the mid 1970s. Rat tumor models have a series of advantages when compared to mouse models despite the recent and frequent use of knockout genetic mice models.

It was first reported in the early 1970s that central nervous system (CNS) tumors could be reproducibly and

\footnotetext{
Laboratory of Experimental Oncology, Physiology and Pharmacology Department, Universidade Federal do Ceará, Fortaleza CE, Brazil.

${ }_{1}^{1}$ Pediatric hemato-oncologist, Hospital Infantil Albert Sabin, Fortaleza CE, Brazil;

${ }^{2}$ Professor of Pharmacy, Department of Pharmacy, Faculdade de Farmácia, Odontologia e Enfermagem, Universidade Federal do Ceará (UFC), Fortaleza CE, Brazil;

${ }^{3}$ UFC, Fortaleza CE, Brazil;

${ }^{4}$ Professor of Pathology, Pathology and Forensics Department, Faculdade de Medicina, UFC, Fortaleza CE, Brazil;

${ }^{5}$ Professor of Pharmacology, Physiology and Pharmacology Department, Faculdade de Medicina, UFC, Fortaleza CE, Brazil.

Correspondence: Francisco H. C. Felix; Hospital Infantil Albert Sabin; Rua Tertuliano Sales 544; 60410-790 Fortaleza CE - Brasil; E-mail:helderfelix@hias. ce.gov.br

Conflict of interest: There is no conflict of interest to declare.

Received 01 November 2010; Received in final form 05 August 2011; Accepted 12 August 2011
} 
selectively induced in adult rats after treatment with chemical carcinogens. These studies led to the development of a number of implanted rat brain tumor models that were highly reproducible ${ }^{1,2}$.

W256 tumor has been used in a number of brain tumor animal models or CNS heterotopic tumor growth models ${ }^{3,4}$. Morreale et al. ${ }^{5}$ developed an improved technique to transplant tumors to the CNS of rats, resulting in more efficient tumor growth in brain parenchyma, less invasion of adjacent structures (meninges, skull bone, subcutaneous tissue and skin) and less distant dissemination. We had modified the model of Morreale, manually inoculating cellular suspensions obtained from in vivo solid tumors (in contrast to the in vitro cell source usually used), aiming at the simplicity and easiness of reproduction of the brain tumor model. We, then, treated animals bearing brain tumors with dexamethasone, an immunosuppressant widely used to treat tumor-related brain edema, and with cyclosporine (CS), a candidate drug for chemotherapy multidrug resistance reversal.

\section{METHODS}

wWalker carcinosarcoma tumor was maintained in vivo by intramuscular inoculation of $1.0 \times 10^{6}$ tumor cells, obtained from previous generation of tumor bearing animals in the hind limb of 150-200 g Wistar rats (Rattus norvegicus), every 9 days.

\section{Drugs}

Drugs used were of analytical grade or commercially available. Dexamethasone phosphate $4 \mathrm{mg} / \mathrm{mL}$ (Prodome, Brazil) and cyclosporine $100 \mathrm{mg} / \mathrm{mL}$ (Biosintetica, Brazil) were used for treatment. Cyclosporine was extemporaneously manipulated for i.p. use as published elsewhere ${ }^{6}$.

\section{Timeline of experiments}

Animals were operated to implant an apparatus comprised of a cannula for tumor inoculation, stereotactically positioned. After this, animals received saline (SHAM) or a tumor cell suspension and the indwelling cannula was occluded. Treated animals received drugs and their survival was annotated as outlined in next sections. Animals were euthanized after a predefined time for tumor volume estimation.

\section{Animals and inoculation}

Male Wistar rats (200-250 g) had a cannula stereotactically implanted in the target point of the CNS (anteriorposterior $=1.5 \mathrm{~mm}$; lateral $=3.0 \mathrm{~mm}$; dorsoventral $=4.0 \mathrm{~mm}$; in relation to bregma). Cannulas were crafted as previously described and were occluded with a needle so that its tip went $2.0 \mathrm{~mm}$ below the cannula tip ${ }^{6}$. This procedure created a pocket where, after 5-15 days (mean 8), a cell suspension with 6.0-7.0x10 viable W256 tumor cells in $1 \times 10^{-6} \mathrm{~L}$ volume was manually inoculated using a $25 \mu \mathrm{L}$ syringe (model 702 80400, Hamilton Co., Reno-Nevada-USA). After inoculation, we waited 5 minutes to permit diffusion of cell suspension into the interstitial fluid. Cell suspension was prepared from solid W256 tumors, using a method previously described 7 . Cell viability was tested in the cell suspension by Trypan blue staining ${ }^{7}$. Animal handling and all the procedures followed the requirements of the Institutional Ethics Board on the Use of Animals in Experimentation. Ether handling and using is not prohibited in our Institution and followed strict safety rules.

\section{Experimental groups}

Experiments were carried out with groups of six animals each, in triplicate ( $\mathrm{n}=18$ per treatment). Only dexamethasone treated animals were different: 12 animals received $0.3 \mathrm{mg} / \mathrm{kg} /$ day and 6 animals received $3.0 \mathrm{mg} / \mathrm{kg} /$ day. A SHAM-operated group received a cell-free isotonic saline inoculated after cannula implantation. Tumor inoculated animals were treated with vehicle (saline or CS diluent, control group), dexamethasone 0.3 or $3.0 \mathrm{mg} / \mathrm{kg} /$ day or CS $10 \mathrm{mg} / \mathrm{kg} /$ day in daily i.p. injections beginning 7 days before tumor inoculation (dexamethasone treatment has begun 4 days after inoculation). Tumor volume estimation (TVE) was performed in 2 animal groups inoculated with tumor cell suspension that developed brain tumors, but were killed seven or nine days after inoculation $(\mathrm{n}=16)$.

\section{Animal examination and sample handling}

Animals from SHAM, control and CS treated groups had routine laboratorial exams performed (10 animals each group). Blood samples were collected from retroocular plexus of rats with capillary tubes seven days after tumor cell inoculation and used to blood cell counting and creatine dosage. Automated total white blood cells count was done (C-6, Beckman Coulter, CA - USA). Neutrophil and lymphocyte count was done manually in May-Grümwald-Giemsa stained slides. Values obtained were classified according to reference values ${ }^{8}$. The main goal of these exams was testing cyclosporine safety, not dexamethasone, so the animals treated with the latter drug were not tested.

Animals from all groups (seven per group) were weighed throughout the experiment: before apparatus implantation, on the $5^{\text {th }}$ day post-inoculation (5d) and on the day of death or euthanasia. Organs were inspected macro- and microscopically for evidence of dissemination and weighed just after euthanasia (except for dexamethasone treated animals, as the main purpose was detect metastasis facilitation by CS). Animals were checked twice daily for their status. When an animal was found dead, its survival (expressed in days from the tumor inoculation procedure) was registered. 
When an animal showed signs of imminent death, it suffered euthanasia by ether inhalation ${ }^{9}$ and its survival was registered. Animals used for TVE suffered euthanasia by intracardiac fixative perfusion ${ }^{9}$, after deep anesthesia by ether inhalation. SHAM animals suffered euthanasia by ether inhalation. Organs were fixed by immersion in 20 times their volumes of neutral buffered $10 \%$ formalin fixative. Two independent pathologists revised the sections and described brain (tumor cell appearance, organization, normal tissue infiltration, meningeal tumor growth, inflammatory infiltrates, hemorrhage and necrosis), lungs and liver (search for metastatic foci), kidneys (looking for interstitial or parenchymatous changes).

TVE group brain slides were used for calculation of tumor volume (TV) and doubling time (DT). Sections previously compared with stereotactic atlas pictures for proper localization were observed with an ocular micrometer (20 times magnification). The tumor diameters were measured in millimeters in each section. TV was calculated assuming that inoculation point was roughly in the center of the tumor, using a modified ellipsoid volume calculation formula, as previously described ${ }^{10}$. Measures taken from animals that suffered euthanasia 7 or 9 days after inoculation were used to calculate the DT, expressed as the time length in hours necessary to duplicate tumor volume. DT was calculated as previously described $^{10}$.

\section{Statistical analysis of data}

Data were electronically registered and summarized using Microsoft Excel (Microsoft Corporation, USA). All statistical tests were performed with R 2.X (R Development Core Team, 2009). Hematological, biochemical, weight and tumor volume results were showed as mean and standard deviation of mean (mean $\pm \mathrm{SD})$. Univariate comparison between groups was performed with student's $t$-test or one-way ANOVA (Tukey as post-hoc test). Multivariate comparison was performed with mixed effects model ANOVA (Bonferroni test as post-hoc), linear regression, binomial logistic regression and multinomial logistic regression. Survival of animals was presented as median and compared with log-rank test and Cox proportional hazards regression. Alpha-type error level for significance was 0.05 .

\section{RESULTS}

Only animals that had an uneventful experimental procedure were included in the study. Ninety-five per cent of the animals successfully inoculated developed brain tumors (data not shown). Only animals that developed brain tumors were used in this study. Three animals were excluded because of wound infection. The median of survival time for control group was 10 days. No dissemination was identified in lungs and liver. Fourteen of the control animals were examined for tumor growth outside the inoculation point. Tumor growth related to the inoculation site was seen in bony skull in four animals. The animals that suffered euthanasia for TVE measurements showed no tumor growth outside the inoculation point.

\section{Brain tumor and TVE}

Brain tumors were formed by small and medium-sized round cells with regular cell shape, nucleus with reticular chromatin and prominent nucleoli. Cells were undifferentiated and highly mitotic (30 mitosis by high power magnification field). Tumors formed nodules centered at the inoculation point with necrotic foci and many satellite nodules. They were not encapsulated, and tumor cells infiltrated deeply into normal brain, perivascular spaces and white matter tracts, like corpus callosum (Fig 1). There were tumor necrosis and hemorrhagic areas (41.7\% of tumors), as well as deposits of a fibrinoid proteinaceous material and vascular neoformation. There were tumor cell infiltrations in the meninges of $97.5 \%$ of the analyzed animals. Some tumors showed intense infiltration by neutrophils (33.3\%).

Estimated TV at day $7(\mathrm{n}=12)$ was $17.08 \pm 6.7 \mathrm{~mm}^{3}$, and at day 9 was $67.25 \pm 19.8 \mathrm{~mm}^{3}(\mathrm{n}=4)$. We assumed that tumor growth was log linear between days 7 and 9 in order to estimate DT. Calculated value was 24.25 h. The measure of largest tumor diameter, but not estimated volume, was correlated significantly with neutrophil infiltration, but not with other histological features observed (linear regression, $\mathrm{p}<0.05, \mathrm{R}^{2}=0.6, \mathrm{~F}$ value $=3.2$ ).

\section{Hematological and biochemical results}

Comparison of hematological values between groups by multinomial logistic regression disclosed no statistically significant difference (Table 1). Mean serum creatine levels were not significantly different between groups (ANOVA).

\section{Weight of animals and organs}

Control animals showed a statistically significant weight loss in the second week after implantation (mean reduction $10 \%$ ), suggesting tumor-induced cachexia (Mixed model ANOVA, Bonferroni test, $\mathrm{p}<0.01, \mathrm{DF}=8, \mathrm{~F}$ value=9.7) (Table 2). SHAM animals showed a normal behavior of gaining weight with time. All tumor-bearing animals showed a significant difference from SHAM animals in the last measure (second week), irrespective of treatment. Cyclosporine treated animals showed a statistically significant weight loss beginning in the first week after implantation, suggesting accelerated cachexia induction (Mixed model ANOVA, Bonferroni test, $\mathrm{p}<0.05, \mathrm{DF}=8, \mathrm{~F}$ value=9.7). Mean brain weight was significantly higher in control and CS groups than in SHAM group ( $p<0.05$, ANOVA). The same did not occur with mean lung or liver weight (Table 3). 

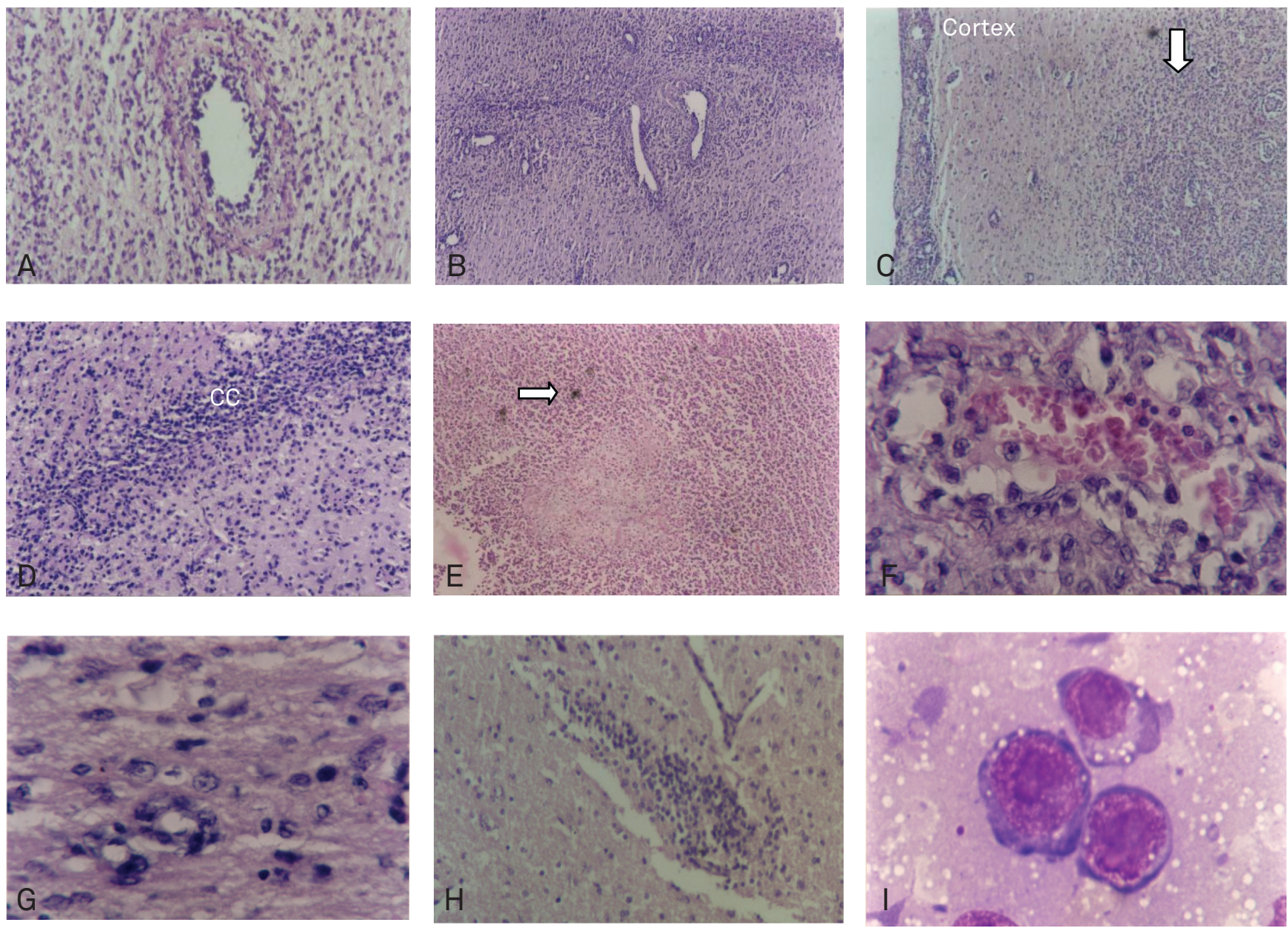

Fig 1. (A) Perivascular cell infiltration and fibrinoid deposits. (X100) (B) Brain tumor angiogenesis. Blood vessels of variable diameters can be observed in the caudate area inoculated with tumor. Usually there's no blood vessel of this size in this area. (X40) (C) Meningeal tumor infiltration. Tumor focal mass grows without a clear border below cortex (arrow) and shows pial meninx neoplastic infiltration. (X40) (D) Tumor dissemination along white matter tract (callosum). Tumor cells invade a section of corpus callosum (CC) ipsilateral to the tumor inoculation point. (X100) (E) Necrosis. Central tumor necrosis, polymorphonuclear cell infiltration and scattered hemosiderin deposits (arrow). (X40) (F) Intratumoral focal hemorrhage. (X400) (G) Perineuronal infiltration. Detail of normal surrounding brain tissue densely infiltrated by migrating tumor cells. (400X) (H) Satellite nodule. Focal tumor nodule grows at the contralateral brain side. (X100) (I) Tumor cell. W256 tumor cell in imprinting preparation. (X1000, oil immersion). Paraffin embedded, hematoxylin-eosin (HE) stained.

Table 1. Neutrophil and lymphocyte counts in animals with and without brain tumor.

\begin{tabular}{lccc} 
& WBC & Neutrophils & Lymphocytes \\
\cline { 2 - 4 } & $\mathrm{n} \times 10^{3}$ & $\mathrm{n} \times 10^{3}$ & $\mathrm{n} \times 10^{3}$ \\
\hline $\begin{array}{l}\text { SHAM } \\
(\mathrm{n}=10)\end{array}$ & $11.1 \pm 3.0$ & $\begin{array}{c}1.5 \pm 0.4 \\
(15 \%)\end{array}$ & $\begin{array}{c}9.2 \pm 2.7 \\
(83 \%)\end{array}$ \\
$\begin{array}{l}\text { Control } \\
(n=10)\end{array}$ & $13.2 \pm 2.6$ & $2.2 \pm 1.3$ & $10.6 \pm 2.6$ \\
CS & & $(17 \%)$ & $(80 \%)$ \\
$(n=10)$ & $10.7 \pm 2.1$ & $2.2 \pm 0.8$ & $8.1 \pm 2.1$ \\
& & $(21 \%)$ & $(76 \%)$
\end{tabular}

Automated total WBC count was done (Coulter C-6). Neutrophil and lymphocyte count was done manually in May-Grümwald-Giemsa stained slides. We report mean $\pm S D$ and relative frequencies to WBC (between brackets). CS: cyclosporine treated. Differences were not statistically significant (multinomial logistic regression). WBC: white blood cell. SHAM: isotonic saline.
Table 2. Weigh evolution in animals inoculated with tumor $($ mean $\pm \mathrm{SD})$.

\begin{tabular}{lccc} 
& \multicolumn{3}{c}{ Weight (g) } \\
\cline { 2 - 4 } & Surgery & $\begin{array}{c}5 d \\
\text { (SHAM: 15d) }\end{array}$ & $\begin{array}{c}\text { Death or euthanasia } \\
\text { (SHAM: } 21-27 d)\end{array}$ \\
\hline $\begin{array}{l}\text { SHAM } \\
(n=7)\end{array}$ & $218 \pm 23$ & $224 \pm 28$ & $249 \pm 31$ \\
Control & $214 \pm 25$ & $210 \pm 20$ & $193 \pm 32$ \\
$(n=7)$ & & $(-2 \%)$ & $(-10 \%)^{\star}$ \\
CS & $216 \pm 14$ & $185 \pm 14$ & $181 \pm 24$ \\
$(n=7)$ & & $(-25 \%)^{\dagger \star}$ & $(-26 \%)^{\dagger \star}$ \\
Dexa & $204 \pm 9$ & $231 \pm 14$ & $204 \pm 19$ \\
$(n=7)$ & & $(13 \%)^{\dagger}$ & $(0 \%)^{\star}$ \\
\hline
\end{tabular}

Animals were weighted on surgery day, 5 days after inoculation ( $5 d$ ) and on death or euthanasia day. Variation rates (\%) within groups comparing to weigh on surgery day are shown between brackets. Weigh averages were compared between and within groups in each occasion. CS: cyclosporine treated. Dexa: dexamethasone treated. SHAM: isotonic saline.

${ }^{*} \mathrm{p}<0.05$ between groups, comparing to SHAM, Mixed-model ANOVA Bonferroni.

${ }^{+} p<0.05$ within groups, comparing to initial weigh, Mixed-model ANOVA, Bonferroni. 
Table 3. Brain and lung weigh in animals inoculated with tumor (control and CS-treated) and SHAM.

\begin{tabular}{lccccc} 
& Body weight $(\mathrm{g})$ & Brain $(\mathrm{g})$ & Lungs $(\mathrm{g})$ & Liver $(\mathrm{g})$ & Kidneys (g) \\
\hline $\begin{array}{l}\text { SHAM } \\
(\mathrm{n}=7)\end{array}$ & $179 \pm 28$ & $1.58 \pm 0.1$ & $1.3 \pm 0.5$ & $6.8 \pm 0.6$ & $1.4 \pm 0.2$ \\
$\begin{array}{l}\text { Control } \\
(\mathrm{n}=7)\end{array}$ & $186 \pm 29$ & $1.95 \pm 0.2$ & $1.7 \pm 0.4$ & $7.8 \pm 0.9$ & $1.7 \pm 0.1$ \\
CS & & $(24 \%)^{\star *}$ & & & $7.3 \pm 1.7$ \\
$(\mathrm{n}=7)$ & $171 \pm 26$ & $1.83 \pm 0.1$ & $1.5 \pm 0.6$ & $1.5 \pm 0.2$ \\
\hline
\end{tabular}

Animals had their bodies weighted and their organs dissected and weighted after death or ether euthanasia. We report mean \pm SD. Ratio from control or CS groups to SHAM group (\%) between brackets. CS: cyclosporine treated. SHAM: isotonic saline.

${ }^{\star} \mathrm{p}<0.05$, ANOVA.

$\star \star p<0.001$, ANOVA.

\section{Pharmacological treatment}

Dexamethasone and CS treated animals median survival was 9.0 (dexa 3.0), 9.5 (dexa 0.3) and 10 (CS) days. Comparison of survival functions by log rank test disclosed a significant difference to control only for dexamethasone $3.0 \mathrm{mg} / \mathrm{kg} / \mathrm{day}$. A Cox proportional hazards regression confirmed that, of all the treatments, only the highest dose of dexamethasone diminished survival of animals in this model $(\mathrm{HR}=4.2, \mathrm{p}<0.01$, $\mathrm{DF}=3$, likelihood ratio=7.1). The frequency of histological features did not vary significantly with CS treatment (logistic model). Cyclosporine did not modify significantly mean brain weight comparing to control group (Fig 2).

\section{DISCUSSION}

We obtained a highly malignant and invasive brain tumor model. Treatment with CS, a specific $\mathrm{T}$ lymphocyte inhibitor, was safely tolerated and did not affect survival in this model despite its induction of an accelerated cachexia. Cyclosporine is an immunosuppressant that has been shown to possess intrinsic antitumor activity ${ }^{11}$ and to inhibit p-glycoprotein, a multidrug resistance protein that is a candidate target for brain tumor chemosensitivity modulation ${ }^{12}$. We may conclude that further pre-clinical and clinical testing with CS in brain tumors is warranted.

The model presented here showed good reproducibility. Meningeal dissemination seems to be a late occurrence in this model, and did not modify survival median time (data not shown). The time between surgery and inoculation procedure permitted blood-brain barrier (BBB) healing and reactive local inflammation resolution. All animals had lesion points localized to the right cerebral hemisphere. Left cortical brain lesions, but not right cortex ones, can induce immune deficits $^{13}$. The short DT during growth log phase indicated that the tumor was fast growing and highly malignant. The presence of satellite nodules near the main tumor mass indicated tumor cell dissemination through any of these three ways: brain parenchyma, perivascular spaces and white matter tracts. Contralateral hemisphere satellite nodule showed that there had been tumor dissemination by cerebrospinal fluid (CSF) circulation routes. Presence of proteinaceous fibrinoid material deposits could indicate fibrinoid necrosis areas. Increase in brain weight was due to local tumor growth, as well as peritumoral brain edema. Lung weight can be used as a quantitative measure of tumor burden in metastatic lung tumorigenesis models ${ }^{14}$. There were no evidence of significant lung or liver metastasis, no macroscopic changes, no organ weight differences and no microscopic alterations in control or CS treated animals. This showed that CS did not enhance metastatic potential in this model.

Primary malignant brain tumors and some extent metastatic tumors show a layer of brain adjacent to tumor (BAT) consisting of tumor cells infiltrating deeply into normal brain tissue, inducing neovascularization. Capillary permeability and blood perfusion in this region are lower than in tumor layer, and drug penetration is impaired ${ }^{15}$. The mechanisms of invasion are similar to that of metastatic process of non-neurologic solid tumors, depend on adhesion molecules expression and are related to induction of angiogenesis ${ }^{16,17}$. In vitro and in vivo laboratory models had been developed aiming the study of CNS tumor invasion. Many transplanted tumors show perivascular invasion, probably related to the presence of the vascular basal layer, rich in extracellular matrix (ECM) structural proteins. Some tumor models show cellular migration along white matter tracts or through CSF circulation routes ${ }^{18}$. Leptomeningeal carcinomatosis is a complication affecting up to $20 \%$ of the patients with some histological types of cancer. Animal models of leptomeningeal metastasis are important to study the physiopathology of meningeal invasion by primary and secondary brain tumors ${ }^{4}$.

It was observed in our model a region probably equivalent to BAT layer. It showed to have intense tumor cell activity, with parenchymatous infiltration, markedly cell tumor migration through white matter tracts (as callosum) and along perivascular spaces. Also, our model showed consistent leptomeningeal metastasis. Intracerebral W256 tumor model developed by Morreale et al. ${ }^{5}$ did not show important invasion of adjacent brain parenchyma. Tumors formed compact, well delimited, masses in contrast to our tumor model. The fact that tumor cells used in this study were obtained in vivo is probably important. Supposedly, these tumor cells from 

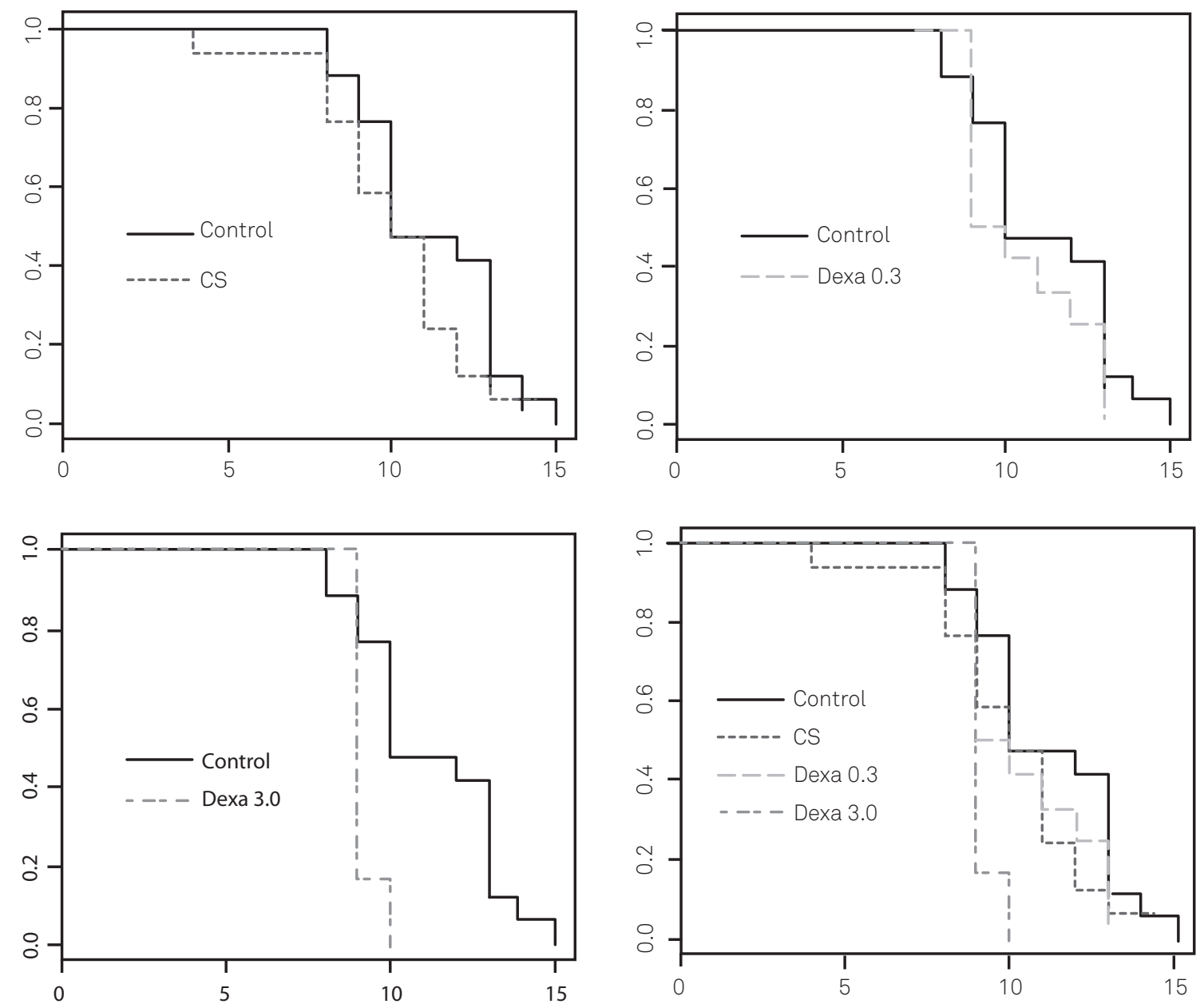

Fig 2. Survival function plots. Survival function was estimated with Kaplan-Meier method and compared with log-rank test. Only treatment with dexamethasone $3.0 \mathrm{mg} / \mathrm{kg} /$ day (Dexa 3.0) was statistically different from control. Cox proportional hazards regression confirmed this.

animal tumors are geno and phenotypically different from in vitro cultivated cells, with diverse potential to invasiveness. The present model constitutes, thus, a potential tool for the research of tumor cell migration and invasion in CNS.

Neoplastic disease related cachexia is caused by the production of a number of cytokines by tumor and inflammatory cells, the most important of them being IL-6, TNF- $\alpha$ and $\mathrm{PGE}_{2}{ }^{19}$. W256 tumor implantation in extraneural sites is associated with cachexia and modified dietetic glucose and lipid metabolism in host animals, as well as induced hypercalcemia, bone mineral density loss and osteoporosis ${ }^{20,21}$. Moreover, W256-induced cachexia is associated with immunosuppression caused by lymphocyte apoptosis. ${ }^{22}$ These metabolic effects of W256 tumor could have contributed to the cachexia presented by the animals of the control group. As far as we are concerned, this is the first experimental account of intracerebral W256 induced cachexia and one of the first experimental brain tumor animal models to show significant cachexia so far. Because of the intracerebral focal growth of the tumor in basal ganglia in this model, there is also the possibility that the animals had developed diencephalic syndrome ${ }^{23}$.

The highest dose of dexamethasone (3 mg/kg/day) showed a statistically significant detrimental effect on survival of animals in this model, but treatment with CS or dexamethasone $0.3 \mathrm{mg} / \mathrm{kg} /$ day did not affect it. Dexamethasone is widely used to treat brain tumor associated edema and has been one of the mainstays of neuro-oncological management of brain tumors for decades ${ }^{24}$. However, its exact modes of action are not yet clarified, and a dose-effect association has not been established. Dexamethasone is thought to reduce tumor capillary leak and mean diffusivity inside the tumor and adjacent edematous brain, affecting both transcellular and paracellular endothelial transports and inducing metalloproteinase inhibitors ${ }^{25}$. Edema from highly malignant tumors, such as brain metastases and glioblastoma, responds to the highest degree, and the impact on other tumor types is less prominent ${ }^{24}$. Additionally, the benefits of steroids must be carefully balanced with its cumbersome and frequent side effects, sometimes life-threatening. Moreover, despite a 
possible direct effect of dexamethasone in glioblastoma cells, it has been suggested that it could protect tumor cells from chemotherapy, hence affecting patient survival ${ }^{26}$. We could show a direct relationship between polymorphonuclear cell infiltrate and tumor diameter in this model. One can postulate tentatively that possibly the tumor infiltrating inflammatory cells play a role in this tumor model, an event already observed in other tumor types ${ }^{27}$. Neutrophil infiltration could possibly have had influence in survival modulation by dexamethasone. Unfortunately, we did not prospectively compared histology in all the treatments, so we are unable to answer whether dexamethasone reduced neutrophil infiltration as well. The lack of protection from dexamethasone in this model and, additionally, its detrimental effect in survival deserve further experimental clarification in order to find the mechanisms of action of dexamethasone in this particular model.
In conclusion, rat brain simplified implantation of W256 tumor model showed to be highly reproducible, yielding undifferentiated highly malignant tumor with local invasive characteristics similar to that of primary brain tumors, and should be a potential model to the study of tumor cell migration in CNS. The model could be used as a tool to investigate biological behavior and novel treatment options for both brain parenchymatous tumor growth and leptomeningeal carcinomatosis. Brain tumor growth induced significant cachexia, and this model could potentially be used to study diencephalic syndrome. Its attractive points are in vivo tumor origin, easy manual inoculation technique and high intracerebral tumor growth yielding. Dexamethasone, a drug widely used in brain tumor patients, reduced survival in this model. The same did not happen with CS treatment. Cycloporine treatment did not affect adversely tumor-bearing animals. Cyclosporine could thus be used for further testing against brain tumor models.

\section{References}

1. Barth RF, Kaur B. Rat brain tumor models in experimental neuro-oncology: the C6, 9L, T9, RG2, F98, BT4C, RT-2 and CNS-1 gliomas. J Neurooncol 2009:94:299-312.

2. Peterson DL, Brown Jr WE. Animal models for brain tumors. In: Black PM, Loeffler JS (Eds). Cancer of the nervous system. USA: Blackwell Science, 1997.

3. Huang TY, Arita N, Hayakawa T, Ushio Y. ACNU, MTX and 5-FU penetration of rat brain tissue and tumors.J Neurooncol 1999;45:9-17.

4. Nakagawa H, Yoshioka K, Miyahara E, Fukushima Y, Tamura M, Itoh K. Intrathecal administration of Y-27632, a specific rho-associated kinase inhibitor, for rat neoplastic meningitis. Mol Cancer Res 2005;3:425-433

5. Morreale VM, Herman BH, Der-Minassian V, et al. A brain-tumor model utilizing stereotatic implantation of a permanent cannula. J Neurosurg 1993;78:959-965.

6. Félix FHC. Modelo de implante de tumor de Walker no cérebro de ratos [dissertação]. Fortaleza: Faculdade de Medicina. Universidade Federal do Ceará; 2001.

7. Freshney RI. Culture of animal cells. New York: Alan R. Liss, 1987.

8. Smith CA, Andrews CM, Collard JK, Hall DE, Walker AK. A color atlas of comparative diagnostic and experimental hematology. Barcelona: Wolfe Publishing, 1994.

9. American Veterinary Medical Association Panel on Euthanasia. 2000 Report of the AVMA Panel on Euthanasia. J Am Vet Med Assoc 2001;218:669-696.

10. Steel GG. Growth Kinetics of Tumours. Oxford: Claredon Press, 1977.

11. Sliwa M, Markovic D, Gabrusiewicz K, et al. The invasion promoting effect of microglia on glioblastoma cells is inhibited by cyclosporin A. Brain 2007;130:476-489.

12. Aller SG, YuJ, Ward A, et al.Structure of P-glycoprotein reveals a molecular basis for poly-specific drug binding. Science 2009;323:1718-1722.

13. Dunn AJ. Interactions between the nervous system and the immune system. Implications for psychopharmacology. In: Bloom FE, Kupfer DJ (Eds). Psychopharmacology: The Fourth Generation of Progress. New York: Raven Press, 1995.

14. Sava G, Clerici K, Capozzi I, et al. Reduction of lung metastasis by ImH[trans-RuCl4(DMSO)Im]: mechanism of the selective action investigated on mouse tumors. Anticancer Drugs 1999;10:129-138.

15. Giese A, Bjerkvig R, Berens ME, Westphal M. Cost of migration: invasion of malignant gliomas and implications for treatment. J Clin Oncol 2003;21:1624-1636.

16. Silva RG, Tavora B, Robinson SD, et al. Endothelial alpha3beta1-integrin represses pathological angiogenesis and sustains endothelial-VEGF. Am J Pathol 2010;177:1534-1548.

17. Gao CF, Xie Q, Su YL, et al. Proliferation and invasion: plasticity in tumor cells. Proc Natl Acad Sci U S A 2005;102:10528-10533.

18. Shelton LM, Mukherjee P, Huysentruyt LC, Urits I, Rosenberg JA, Seyfried TN. A novel pre-clinical in vivo mouse model for malignant brain tumor growth and invasion.J Neurooncol 2010;99:165-176.

19. Rebeca R, Bracht L, Noleto GR, et al. Production of cachexia mediators by Walker 256 cells from ascitic tumors. Cell Biochem Funct 2008;26: 731-738.

20. Fernandes LC, Machado UF, Nogueira CR, Carpinelli AR, Curi R. Insulin secretion in Walker 256 tumor cachexia. Am J Physiol 1990;258: 1033-1036.

21. Waki Y, Miyamoto K, Kasugai S, Ohya K. Osteoporosis-like changes in Walker carcinoma 256-bearing rats, not accompanied with hypercalcemia or parathyroid hormone-related protein production. Jpn J Cancer Res 1995;86:470-476.

22. Lima TM, Lima MM, Almeida DC, Mendonça JR, Curi R. Cachexia induced by Walker 256 tumor growth causes rat lymphocyte death. Cancer Immunol Immunother 2005;54:179-186.

23. Fleischman A, Brue C, Poussaint TY, et al. Diencephalic syndrome: a cause of failure to thrive and a model of partial growth hormone resistance. Pediatrics 2005;115:742-748.

24. Kotsarini C, Griffiths PD, Wilkinson ID, Hoggard N. A systematic review of the literature on the effects of dexamethasone on the brain from in vivo human-based studies: implications for physiological brain imaging of patients with intracranial tumors. Neurosurgery 2010;67:1799-1815.

25. Gu Y, Qin L, Qin X, Xu F. The molecular mechanism of dexamethasonemediated effect on the blood-brain tumor barrier permeability in a rat brain tumor model. Neurosci Letters 2009;452:114-118.

26. Qian $\mathrm{YH}$, Xiao Q, Chen $\mathrm{H}$, Xu J. Dexamethasone inhibits camptothecininduced apoptosis in C6-glioma via activation of Stat5/Bcl-XL pathway. Biochim Biophys Acta 2009;1793:764-771.

27. Hillen F, Baeten CIM, van de Winkel DC, Van der Schaft DWJ, Winnepenninckx V, Griffioen AW. Leukocyte infiltration and tumor cell plasticity are parameters of aggressiveness in primary cutaneous melanoma. Cancer Immunol Immunother 2008;57:97-106. 